\title{
Quebra do grão em Resíduos de Construção Civil (RCC) induzida pelo processo de compactação
}

\author{
Particle breakage in Construction Waste (CW) induced by \\ compaction
}

\section{Nathália Marques da Silva \\ Heloisa Yukie Ishida \\ J uliana Azoia Lukiantchuki \\ J eselay Hemetério Cordeiro dos Reis Christopher Fonseca da Silva}

\section{Resumo}

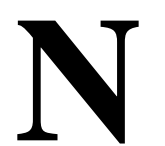

as últimas décadas a geração de resíduos de construção civil (RCC) tornou-se um fator relevante em todo o mundo. Dessa forma, é cada vez mais importante o reaproveitamento desse material, sobretudo em obras de grande consumo, tais como as obras rodoviárias. No entanto, a aplicação desses resíduos depende do conhecimento das propriedades químicas e mecânicas do material. Entre esses parâmetros destaca-se que a susceptibilidade à quebra do grão é de fundamental importância. Isso porque esse parâmetro influencia diretamente no comportamento do material através da resistência e da permeabilidade. O presente trabalho avaliou a quebra do grão em RCC induzida pelo processo de compactação através da aplicação das energias normal e modificada. Para isso o material foi dividido em frações com granulometrias diferentes. Dessa forma, foi analisada a influência da energia, do tamanho do grão, da mineralogia, do teor de umidade e da densidade da amostra. Os resultados indicaram que a ocorrência da quebra do grão está diretamente relacionada com a constituição mineralógica, observando-se que a maior fração estudada foi aquela que sofreu a menor quebra dos grãos. Adicionalmente, os resultados indicaram que a densidade de compactação da amostra também possui significativa influência no processo de quebra dos grãos.

Nathália Marques da Silva Universidade Estadual de Maringá Maringá - PR - Brasil

Heloisa Yukie Ishida Universidade Estadual de Maringá Maringá - PR - Brasil

J uliana Azoia Lukiantchuki Universidade Estadual de Maringá Maringá - PR - Brasil

J eselay Hemetério Cordeiro dos

Universidade Estadual de Maringá Maringá - PR - Brasil

Christopher Fonseca da Silva Universidade Estadual de Maringá Umuarama - PR - Brasil

Recebido em 02/09/16 Aceito em 24/04/17
Palavras-chave: Resíduos de construção civil. Quebra do grão. Compactação.

\section{Abstract}

In recent decades, the generation of construction waste $(\mathrm{CW})$ has become a significant issue throughout the world. Therefore, the reuse of this material is becoming increasingly important, particularly in projects with high material demand, such as road works. However, the application of these waste products depends on knowledge about the chemical and mechanical properties of the material. One parameter of crucial importance is the susceptibility to particle breakage, since it directly influences the behaviour of the material in terms of resistance and permeability. This study evaluated particle breakage in $C W$, induced by compaction through the application of standard and modified energy. In order to do that, the material was divided into fractions of different particle sizes. Then, the influence of each of the following factors was analysed: energy, grain size, mineralogy, moisture content and the density of the sample. The results indicated that the occurrence of particle breakage is directly related to the mineralogical composition, and that the largest fraction studied was the one that suffered the smallest particle breakage. Additionally, the results indicated that the density of compaction of the sample also has significant influence on the process of particle breakage.

Keywords: Construction waste. Particle breakage. Compaction.

SILVA, N. M. da; ISHIDA, H. Y.; LUKIANTCHUKI, J. A.; REIS, J. H. C. dos; SILVA, C. F. da. Quebra do grão em Resíduos 281 de Construção Civil (RCC) induzida pelo processo de compactação. Ambiente Construído, Porto Alegre, v. 18, n. 1, p. 281-298, jan./mar. 2018. 


\section{Introdução}

Atualmente, um dos grandes problemas associados ao crescimento populacional, à expansão urbana e ao desenvolvimento industrial consiste na geração de resíduos sólidos urbanos e industriais de diversos tipos. Isso tem se tornando um sério problema urbano devido, sobretudo, a seu gerenciamento oneroso e complexo, associado à escassez de áreas de disposição, altos custos devido à adoção de medidas ineficientes de gerenciamento, problemas de saneamento público e contaminação ambiental, gerados pela disposição irregular desses resíduos (SANTOS, 2007).

Além disso, entre as indústrias que degradam o meio ambiente, seja ele urbano ou natural, a indústria da construção destaca-se por ser responsável por números entre $20 \%$ e $50 \%$ do total de recursos naturais consumidos pela sociedade (SJOSTROM, 1992) e por gerar cerca de $40 \%$ dos resíduos produzidos pela sociedade em geral. Aliado a esses fatos, observa-se que a maioria das cidades brasileiras não possui área para a disposição final dos resíduos de construção civil (RCC) e que esses resíduos são constituídos por materiais com alto potencial de reciclagem, tornando-se fundamental o estudo de soluções para esse problema ambiental.

A visão de necessidade de implantar uma gestão adequada para esses resíduos no Brasil é recente. Apesar de ter sido nos anos 90 que as usinas recicladoras começaram a se instalar no país, apenas em 2004 foram publicadas as primeiras normas nacionais ligadas ao agregado reciclado de resíduo de construção. A Resolução n 307 outorgada pelo Conselho Nacional do Meio Ambiente (CONSELHO..., 2002) responsabiliza o próprio gerador de resíduos por sua destinação adequada. Essa medida gerou o interesse das empresas construtoras em buscar meios que possibilitem a reutilização do resíduo de construção e demolição em novas obras, e ainda incentivou o desenvolvimento de técnicas construtivas mais sustentáveis, interferindo na quantidade de resíduos gerados por novas construções.

Na última década é crescente o interesse de pesquisas relacionadas à aplicação dos resíduos de construção e demolição na engenharia civil. Diversos pesquisadores (MOTTA, 2005; LEITE, 2007; DISFANI et al., 2011; ARULRAJAH et al., 2014; JIMÉNEZ, 2011) vêm estudando a viabilidade da utilização do RCC para fins de pavimentação. Os resultados encontrados têm sido bastante promissores, indicando alto potencial do emprego desses materiais.
No entanto, segundo Miranda et al. (2009), as normas existentes não são capazes de garantir a homogeneidade dos agregados reciclados, o que limita sua aceitação no mercado de trabalho. Os autores propõem como solução a intensificação do controle de qualidade dos RCC, que possui um custo baixo e possibilitaria reduzir a variabilidade e melhorar a qualidade e a confiabilidade do produto.

Além disso, algumas pesquisas têm demonstrado que, apesar da boa qualidade dos agregados provenientes dos resíduos de construção civil (RCC), ocorre a quebra do grão durante o processo de compactação (JIMÉNEZ, 2011; JIMÉNEZ et al., 2014; MOTTA, 2005). A ocorrência da quebra do grão provoca mudanças no tamanho das partículas dos resíduos de construção e demolição e, consequentemente, nas tensões atuantes.

Lade et al. (1996) estudaram a quebra do grão em partículas de solo e concluíram que a quebra de partículas influencia diretamente importantes propriedades dos solos granulares, tais como resistência à compressão, forma de curva tensãodeformação, alterações volumétricas, dissipação de poro, pressão e permeabilidade. Ghafghazi et al. (2014) conduziram um estudo de quebra do grão em areias através de ensaios triaxiais. Os pesquisadores observaram que a quebra da partícula ocorre juntamente com a dilatância e proporciona uma compressibilidade adicional ao solo. Coop et al. (2004) observaram que durante ensaios de cisalhamento direto os materiais granulares sofrem um severo processo de quebra dos grãos, o que altera a distribuição granulométrica do material. No entanto, os resultados indicaram que essas alterações não alteram o ângulo de atrito interno do solo.

Em relação à pesquisa sobre a quebra do grão em resíduos de construção civil, poucos estudos específicos foram realizados. Jiménez et al. (2014) estudaram a influência do teor de umidade na quebra dos grãos através da curva de retenção dos RCC. Os ensaios foram realizados utilizando-se diferentes energias de compactação com diferentes teores de umidade. O diâmetro dos poros foi relacionado com a sucção matricial através de um modelo de distribuição do tamanho dos poros (PSD). Os resultados indicaram que a influência do teor de umidade na quebra dos grãos pode ser explicada através da sucção matricial desenvolvida dentro dos poros dos agregados. Observou-se ainda que a quebra do grão é fortemente influenciada pela energia de compactação aplicada. Dessa forma, os pesquisadores destacam que o estudo da quebra do grão depende da 
determinação da curva de retenção do material analisado.

Leite et al. (2011) também estudaram a quebra do grão em RCC através de ensaios de compactação utilizando as energias intermediária e modificada. Os autores observaram que o processo de compactação altera o formato das partículas e que, após a compactação, ocorre um aumento de partículas com formato cúbico e diminuição de partículas planas e alongadas. Adicionalmente, os resultados indicaram que o processo de quebra dos grãos é mais intensificado no início da compactação, que é quando o material não se encontra em estado denso, sendo a mobilidade das partículas facilitada. De maneira geral, os autores concluíram que a quebra do grão ocorre durante o processo de construção, e não ao longo da vida útil do pavimento. Além disso, os autores destacam que o processo de quebra das partículas em laboratório se apresenta inferior ao observado em campo, isso porque o cilindro de compactação restringe a mobilidade das partículas.

Este trabalho de pesquisa tem como finalidade estudar o comportamento da quebra do grão em resíduos de construção civil (RCC), submetidos a ensaios de compactação realizados nas energias normal e modificada. Para isso, a amostra de RCC coletada foi peneirada e dividida em quatro frações granulométricas distintas. A quebra do grão foi avaliada através da comparação da distribuição granulométrica antes e após o ensaio de compactação. A comparação dos resultados permitiu avaliar a influência da fração granulométrica, da constituição mineralógica, do teor de umidade e da energia de compactação no processo de quebra dos grãos dos RCC.

\section{Figura 1 - Etapa de coleta da amostra da RCC}

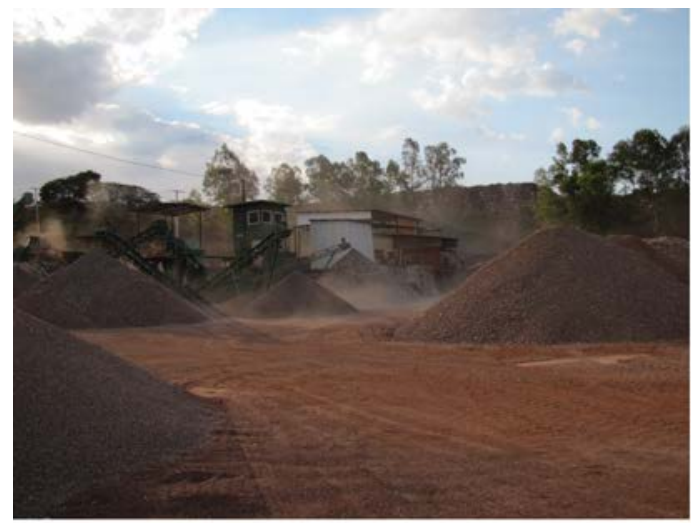

(a) Usina de Reciclagem Mauá

\section{Coleta e caracterização das amostras de RCC}

\section{Coleta e preparo do material}

O resíduo de construção civil (RCC) foi coletado na Usina de Reciclagem Mauá, localizada na cidade de Maringá, PR, Brasil (Figura 1). Para minimizar os problemas quanto à variabilidade da composição do RCC, foram coletados cerca de $400 \mathrm{~kg}$ de material, o que possibilitou a realização de todos os ensaios previstos nesta pesquisa. Esse procedimento contribui para eliminar possíveis variáveis em relação à utilização de diferentes tipos de RCC.

A amostra de RCC foi deixada secar na sombra à temperatura ambiente até atingir o teor de umidade higroscópico. O controle do teor de umidade higroscópico foi efetuado frequentemente observando que os valores determinados ficaram entre 3\% e 7\%. Posteriormente, a amostra foi separada em quatro faixas granulométricas distintas (Figura 2) por peneiramento seco para a obtenção das seguintes frações: 4,8-2,0 mm; 2,0-0,84 mm; 0,84-0,42 mm e <0,42 mm, representando $18 \%$, $15 \%, 17 \%$ e $50 \%$ da fração total respectivamente. A separação granulométrica foi realizada visando estudar a influência do tamanho do grão na quebra das partículas para as diferentes energias de compactação.

Além da diferença do tamanho dos grãos, a Figura 2 também ilustra que as diferentes frações estudadas possuem diferentes formatos de grãos. Para as frações 4,8-2,0 mm e 2,0-0,84 mm, observa-se que o formato dos grãos predominante é angular e subangular, enquanto para a fração 0,84-0,42 mm os grãos também possuem formato subarredondado e arredondado. A fração $<0,42 \mathrm{~mm}$ não possui grãos com formato angular e subangular, sendo constituída basicamente por grãos com formato subarredondado e arredondado.

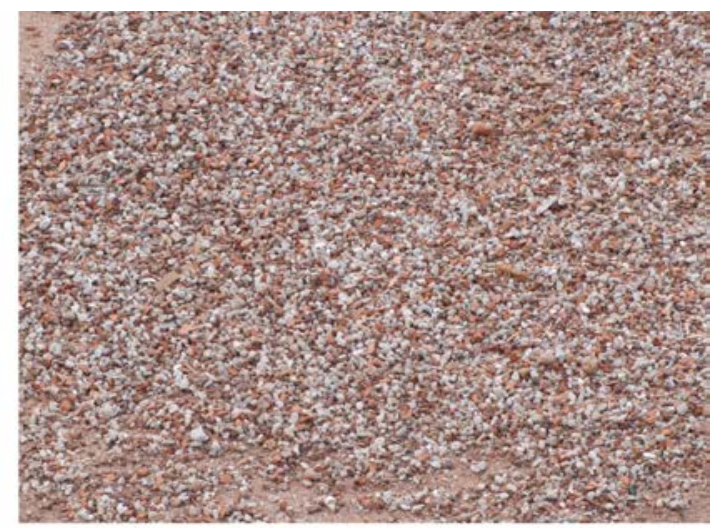

(b) Amostra de RCC 
Figura 2 - Frações do RCC obtidas por peneiramento

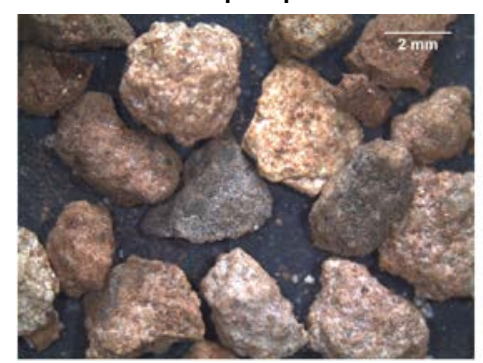

(a) 4,8-2,0 mm

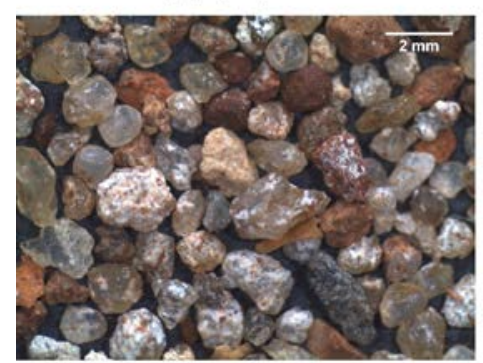

(c) $0,84-0,42 \mathrm{~mm}$

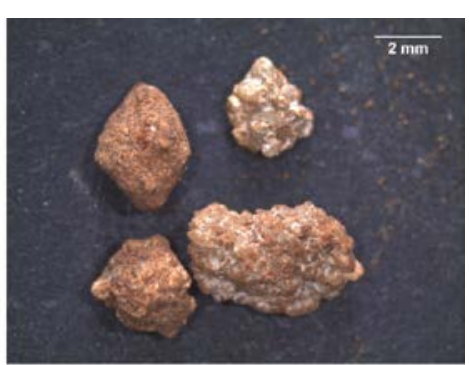

(b) 2,0-0,84 mm

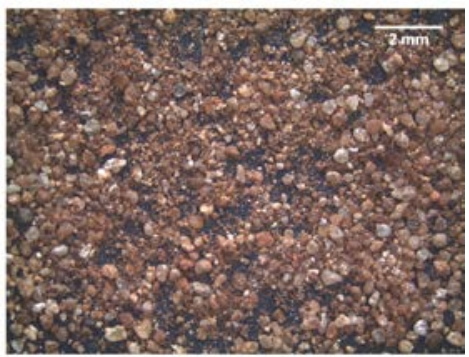

(d) $<0,42 \mathrm{~mm}$

\section{Caracterização mineralógica da amostra de RCC}

A caracterização mineralógica das amostras de RCC foi realizada através do ensaio de difratometria de raios X (DRX). Os ensaios de DRX foram realizados no Centro Brasileiro de Pesquisas Físicas (CBPF), no Rio de Janeiro. Utilizou-se um difratômetro do tipo X'Pert PRO da Panalytical com o objetivo de determinar os minerais predominantes nas diferentes frações do RCC. As frações de RCC foram acondicionadas em um amostrador, e a superfície final foi devidamente nivelada. Para isso, a amostra deveria ser pulverizada, reduzindo-se o tamanho dos grãos. Apenas para a fração 4,8-2,0 mm não foi realizado o ensaio de DRX porque a amostra não foi preparada adequadamente (pulverizada). Os parâmetros para a realização dos ensaios foram radiação $\mathrm{Cu} \mathrm{Kalfa,} 40 \mathrm{kV}$ e $35 \mathrm{~mA}$, com filtro de $\mathrm{Ni}$ e como parâmetros ângulo $(2 \theta)$ entre $5^{\circ}$ e $80^{\circ}$, passo de $0,02^{\circ}$ e velocidade de $3 \mathrm{~s}$ por passo. A identificação dos minerais foi realizada utilizandose o software X'Perth HighScore.

A Figura 3 apresenta o difratograma de raios $\mathrm{X}$ para as diferentes frações estudadas. A interpretação dos difratogramas foi realizada com base em dados disponíveis em Santos (1975), Ângulo et al. (2009), Alexandridou et al. (2014) e Menezes et al. (2009). Ângulo (2005) observou que as fases cristalinas presentes nos RCC pertencem a três grupos de materiais: tectossilicatos (rochas naturais), filossilicatos (argilominerais) e carbonatos e fases de aglomerantes hidratados.

A separação dos RCC em diferentes frações indica que todas as amostras são constituídas por quartzo, feldspato (albita) e calcita. Entretanto, observa-se que para as diferentes frações estudadas os minerais encontram-se em diferentes quantidades. O quarto e o feldspato são minerais abundantes na natureza e presentes nas rochas naturais. A calcita encontra-se presente nos RCC devido à presença do cimento $\mathrm{e}$ possivelmente da cal. Os difratogramas indicam também a presença de alguns argilominerais, tais como muscovita, flogopita, ilita, caulinita e biotita. Ângulo (2005) observou que o tipo dos argilominerais varia de acordo com a procedência dos RCC. A presença dos argilominerais micáceos ficou mais evidente nas frações 2,0-0,84 mm e < 0,42 mm. Para a fração 0,84-0,42 mm observou-se a presença de caulinita. A presença dos argilominerais micáceos pode estar relacionada com rochas de granito e cerâmicas de argila vermelha (ÂNGULO et al., 2009). Destaca-se que apenas os ensaios de DRX não possibilitam uma determinação quantitativa precisa dos minerais constituintes das frações. A identificação precisa dos minerais constituintes das frações depende de ensaios complementares, tais como o ensaio de DRX com lâminas tratadas (glicolação e efeito de aquecimento) e ensaios de análise termogravimétrica. 
Figura 3 - Difratograma de raios X (DRX) para as diferentes frações estudadas
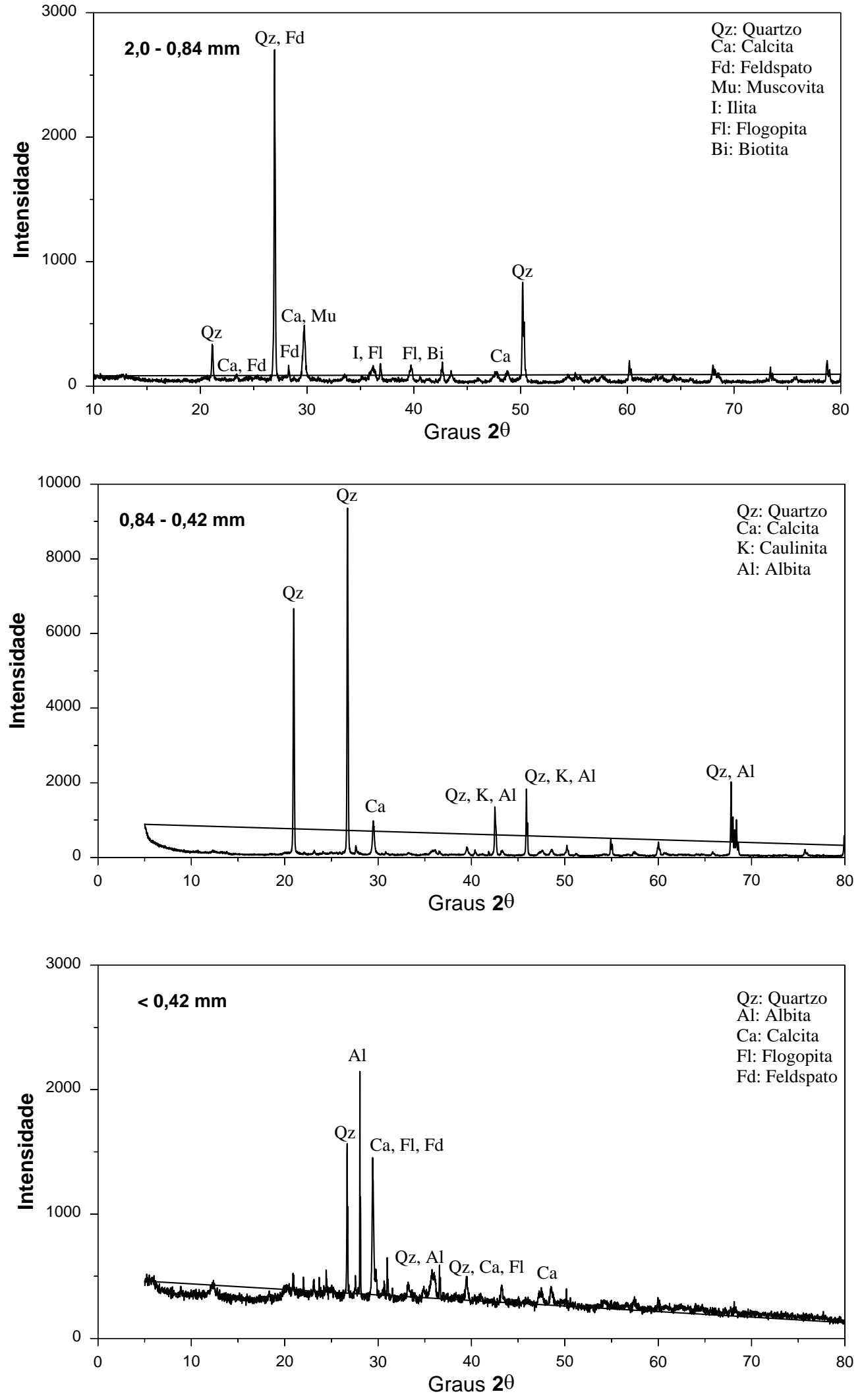
Lasso et al. (2013) observaram que ensaios de DRX realizados em amostras de RCC apresentaram predominância das fases cristalinas do quartzo $\left(\mathrm{SiO}_{2}\right)$ e de carbonato de cálcio $\left(\mathrm{CaCO}_{3}\right)$. Ângulo (2005) estudou a composição dos RCC através do ensaio de DRX, identificando a presença de quartzo, calcita, albita e argilominerais micáceos, tais como muscovita e flogopita. Também foi identificada a etringita, associada à hidratação do cimento.

Adicionalmente foram realizados ensaios para a determinação da massa específica dos grãos $\left(\rho_{\mathrm{s}}\right)$ através do método do picnômetro, seguindo os procedimentos recomendados para amostras de solos (ABNT, 1984a). Considerando que o objetivo do trabalho é quantificar a quebra do grão devido ao processo de compactação das amostras de RCC, optou-se por não utilizar o dispersor após o repouso de $12 \mathrm{~h}$ em água destilada, eliminando a possibilidade de quebra do grão durante esse processo. Observa-se na Tabela 1 que, para as diferentes frações estudadas, a massa específica dos sólidos apresentou valores próximos entre si. Os valores encontrados apresentaram-se ligeiramente superiores a 2,670 g/cm 3 , valor de massa específica dos sólidos característico para amostras com predominância de quartzo. Isso pode ser explicado pela presença de calcita e hematita, que são minerais com valores de massa específica entre $2,700 \mathrm{~g} / \mathrm{cm}^{3}$ e $4,200 \mathrm{~g} / \mathrm{cm}^{3}$ respectivamente (MITCHELL, 1993).

Não foram realizados ensaios de limites de consistência, uma vez que as amostras de RCC se apresentaram com comportamento bastante granular e não indicaram comportamento plástico.

\section{Método proposta para o estudo da quebra do grão}

A metodologia utilizada para a avaliação do efeito da compactação na quebra dos grãos dos resíduos de construção civil (RCC) foi dividida nas etapas indicadas nos fluxogramas apresentados nas Figuras 4 e 5. A Figura 4 apresenta a primeira etapa da pesquisa, em que o principal objetivo foi determinar uma curva granulométrica na condição inicial para as diferentes frações granulométricas (curva de referência $-G_{R}$ ). Nesta etapa foram realizados três ensaios de análise granulométrica $\left(G_{1}, G_{2}\right.$ e $\left.G_{3}\right)$ para cada fração, e, não ocorrendo divergências acentuadas entre os resultados, adotou-se uma curva granulométrica média $\left(\mathrm{G}_{\mathrm{R}}\right)$.

A análise granulométrica foi realizada de acordo com a NBR 7181 (ABNT, 1984b), com exceção do uso do dispersor após o repouso de 12 h na solução de hexametafosfato de sódio, eliminando a possibilidade de quebra do grão durante esse processo.

Na segunda etapa, para cada uma das frações foi realizado o ensaio de compactação nas energias normal e modificada (Figura 5), seguindo os procedimentos da NBR 7182 (ABNT, 1986). Para a fração 2,0-0,84 mm, o material foi inicialmente lavado para a retirada de eventuais finos e deixado secar ao ar livre até atingir o teor de umidade higroscópico. As demais frações, que já estavam secas ao ar livre, foram apenas homogeneizadas.

Antes da compactação as amostras foram previamente umedecidas e deixadas em repouso em câmara úmida por um período de $12 \mathrm{~h}$, para garantir melhor homogeneização das amostras. $\mathrm{O}$ ensaio de compactação foi realizado na energia correspondente, variando-se o teor de umidade em pelo menos 5 pontos ( $\left.\mathrm{w}_{1}, \mathrm{w}_{2}, \mathrm{w}_{3}, \mathrm{w}_{4} \mathrm{e} \mathrm{w}_{5}\right)$. Após a compactação, os corpos de prova foram desmontados, devidamente identificados e deixados secar em bandejas plásticas, para sua secagem até o teor de umidade higroscópico. Em relação à compactação, destaca-se que para algumas frações determinados teores de umidade apresentaram expulsão de água durante o processo de compactação, sobretudo devido à elevada permeabilidade apresentada pelo material.

Posteriormente, cada um dos diferentes pontos foi submetido novamente ao ensaio de análise granulométrica $\left(G_{1}, G_{2}, G_{3}, G_{4}\right.$ e $\left.G_{5}\right)$. A análise comparativa entre a curva granulométrica de referência e a curva granulométrica após a compactação possibilitou avaliar a ocorrência da quebra do grão sob diferentes condições, tais como diâmetro da partícula (diferentes frações), quantidade de água (teor de umidade) e energia de compactação (normal e modificada).

\section{Resultados}

\section{Compactação}

Os resultados dos ensaios de compactação são apresentados no mesmo padrão dos resultados convencionalmente apresentados para os solos. A massa específica seca é relação entre a massa dos grãos e o volume total, o que representa a massa específica quando o grau de saturação for igual a zero. Durante a execução dos ensaios, algumas frações granulares apresentaram quantidade de água em excesso (Figura 6), que, devido ao comportamento drenante do material, possibilitou a expulsão da água quando se aplicou a energia do ensaio. 
Tabela 1 - Resultados de massa específica dos grãos

\begin{tabular}{c|c|c|c|c}
\hline Parâmetro & $\mathbf{4 , 8 - 2 , 0}$ & $\mathbf{2 , 0 - 0 , 8 4}$ & $\mathbf{0 , 8 4 - 0 , 4 2}$ & $<\mathbf{0 , 4 2}$ \\
\hline$\rho_{\mathrm{s}}\left(\mathrm{g} / \mathrm{cm}^{3}\right)$ & 2,820 & 2,760 & 2,780 & 2,790 \\
\hline
\end{tabular}

Figura 4 - Determinação da curva granulométrica de referência $\left(G_{R}\right)$

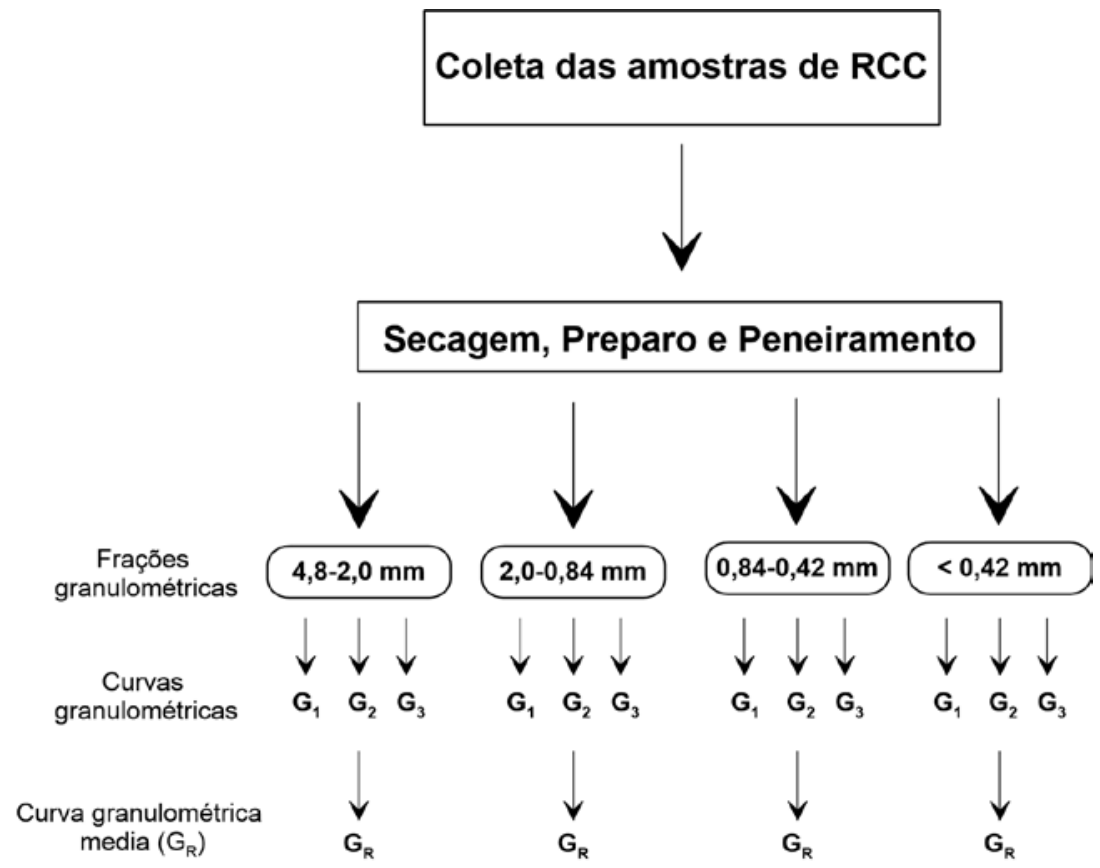

Figura 5 - Compactação na energia normal ou modificada e análise granulométrica pós-compactação Frações granulométricas

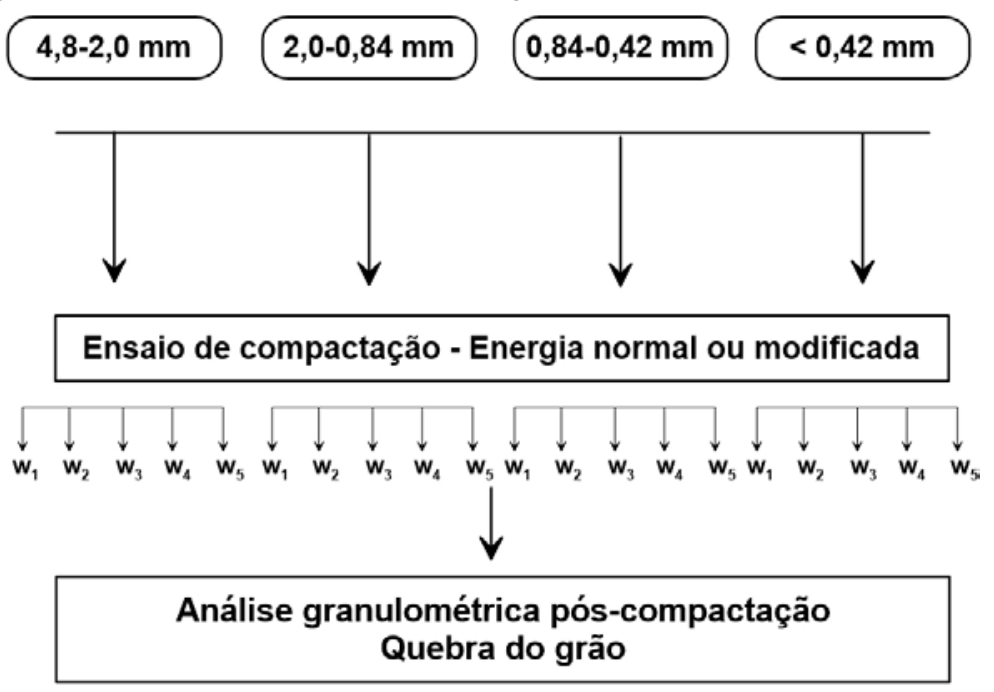

Compactação com diferentes energias e teores de umidade

Curvas granulométricas para diferentes energias e teores de umidade

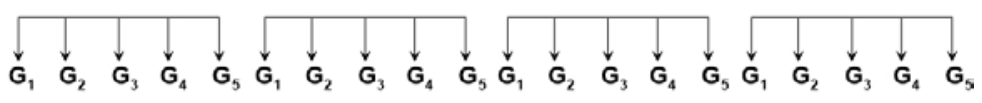<smiles>C1CC1</smiles>

\section{Comparação e análise dos resultados}


Figura 6 - Expulsão de água devido ao processo de compactação

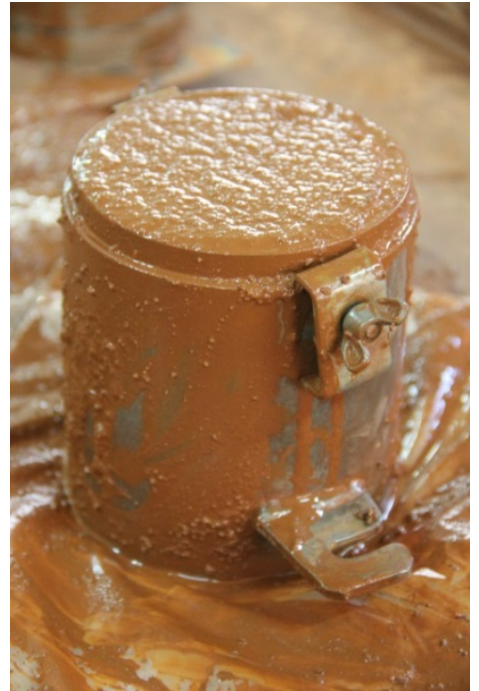

No ensaio de compactação padronizado através da NBR 7182 (ABNT, 1986) são estabelecidos diferentes tipos de energia. Os ensaios deste trabalho foram conduzidos mediante a aplicação da energia normal $\left(600 \mathrm{~kJ} / \mathrm{m}^{3}\right)$ e da energia modificada $\left(2.800 \mathrm{~kJ} / \mathrm{m}^{3}\right)$.

A Figura 7 apresenta as curvas de compactação nas energias normal e modificada para a fração compreendida entre $4,8 \mathrm{~mm}$ e $2,0 \mathrm{~mm}$. Os resultados indicam que para a energia normal a massa específica seca apresenta-se praticamente constante, ocorrendo pouca variação nos valores obtidos. Para esse caso, o valor médio obtido foi de $1,346 \mathrm{~g} / \mathrm{cm}^{3}$ com coeficiente de variação inferior a $2 \%$. No caso da energia modificada, os valores de massa específica apresentaram um ligeiro acréscimo com o aumento do teor de umidade. Entretanto, os resultados indicam que se adotando o valor médio de $1,622 \mathrm{~g} / \mathrm{cm}^{3}$ o coeficiente de variação obtido é de 3,2\%. Observa-se que a massa específica seca para o ensaio na energia modificada apresenta-se cerca de $20 \%$ superior à massa específica seca para o ensaio na energia normal. Arulrajah et al. (2014) investigaram o comportamento de seis tipos de resíduos granulares através de ensaios de laboratório. Esses resíduos eram compostos de resíduos de concreto reciclado, tijolo britado, resíduos de pavimento de asfalto, resíduos de escavação de rocha, vidro fino e médio reciclado. Os autores também observaram que para alguns desses resíduos a massa específica seca apresentou-se insensível ao teor de umidade, alterando-se muito pouco com o aumento de água. Segundo esses autores, esse comportamento insensível pode ser atribuído a materiais mais

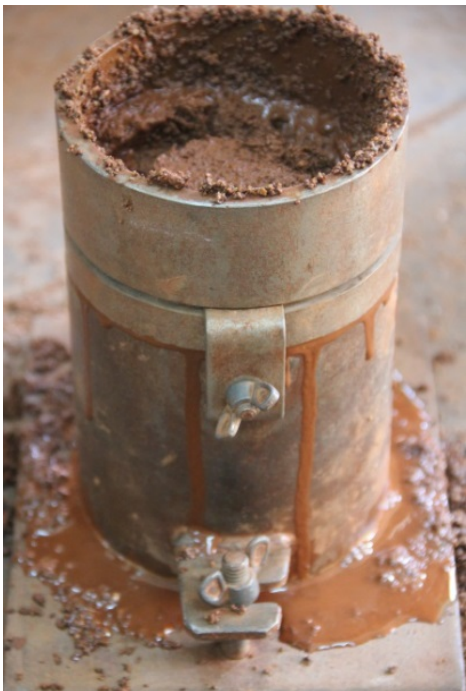

granulares, com superfície lisa, que apresentam baixa absorção de água.

Em relação ao teor de umidade, alguns autores recomendam adotar como teor de umidade ótimo o máximo valor de umidade que se pode atingir sem que ocorra a expulsão da água da amostra (MATUELLA, 2014). Segundo Matuella (2014), como os valores de massa específica seca não variam muito, torna-se interessante trabalhar com a máxima quantidade de água possível, provocando a lubrificação das partículas e auxiliando no processo de compactação. Os resultados indicaram ainda que, apesar da elevada quantidade de água utilizada nos ensaios, os pontos ficaram bastante distantes da curva de saturação $(\mathrm{Sr}=100 \%)$, sobretudo devido ao comportamento de drenagem livre.

A Figura 8 apresenta as curvas de compactação nas energias normal e modificada para a fração compreendida entre $2,0 \mathrm{~mm}$ e $0,84 \mathrm{~mm}$. Os resultados apresentam um comportamento similar ao comportamento observado para a fração 4,82,0 mm. Para o caso da energia normal, os valores de massa específica apresentaram ligeiro acréscimo com o aumento do teor de umidade. Para a energia modificada, o valor médio obtido foi de $1,603 \mathrm{~g} / \mathrm{cm}^{3}$ com coeficiente de variação igual a 3,3\%. O mesmo comportamento foi observado para os resíduos de construção e demolição analisados por Motta (2005). Este autor destaca que os parâmetros de compactação para amostras de resíduos são amplamente variáveis e recomenda que o ensaio deva ser conduzido estabelecendo previamente o teor de absorção da amostra de resíduo. Além disso, para definir o teor de umidade a ser empregado em campo, deve-se evitar o aparecimento de água em excesso (Figura 6). 
Figura 7 - Curvas de compactação (4,8-2,0 mm)

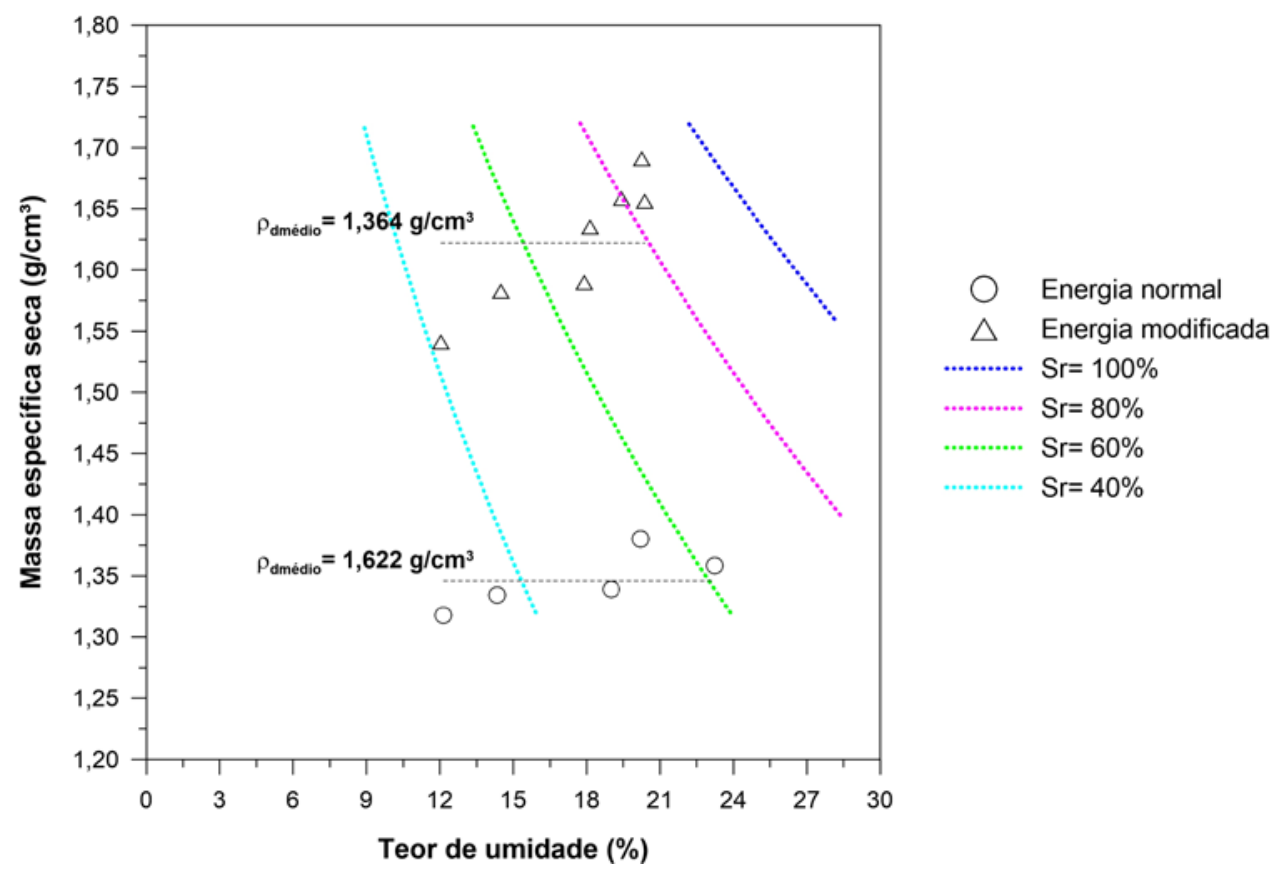

Figura 8 - Curvas de compactação $(2,0-0,84 \mathrm{~mm})$

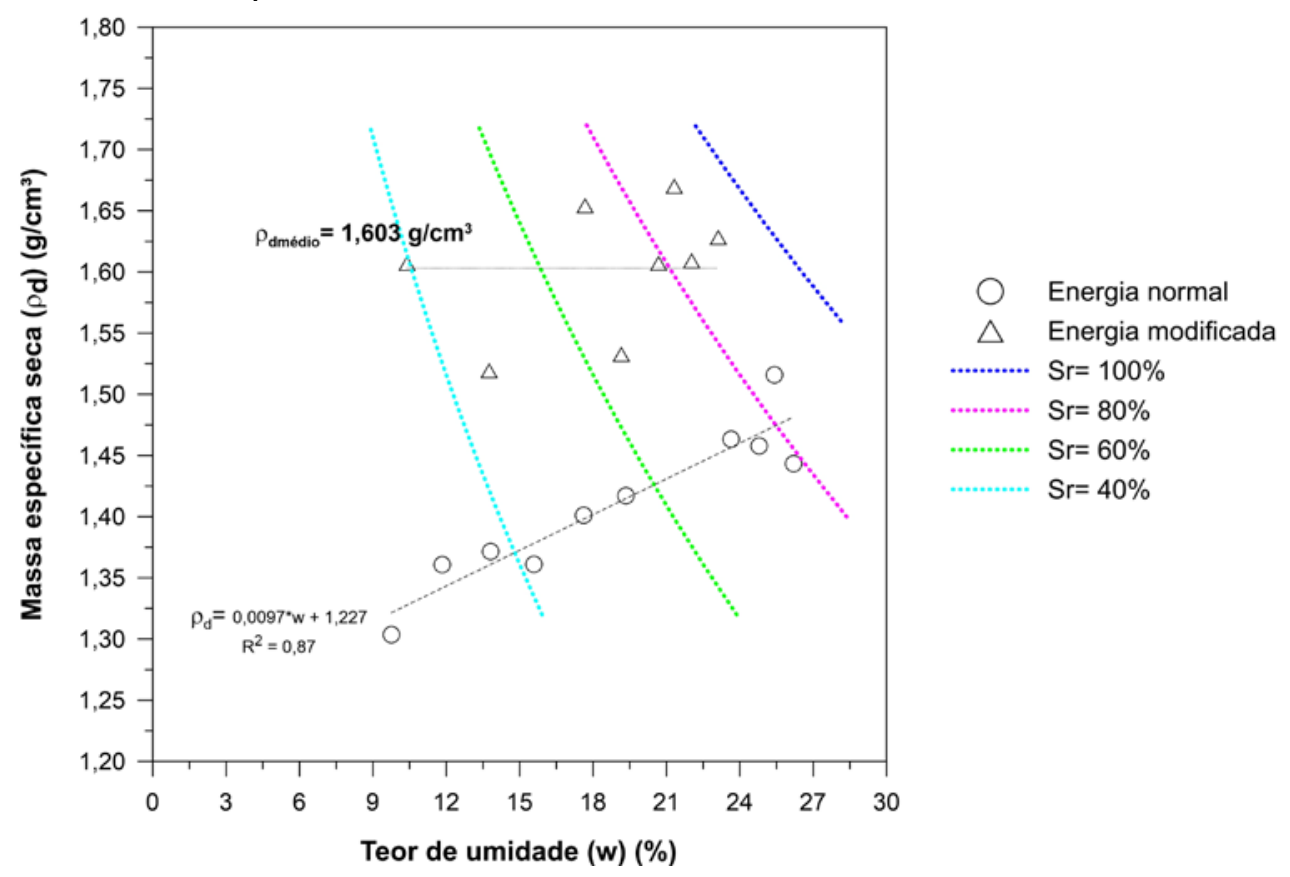

As Figuras 9 e 10 apresentam as curvas de compactação nas energias normal e modificada para as frações correspondentes a 0,84-0,42 mm e < 0,42 $\mathrm{mm}$ respectivamente. Para essas frações os resultados apresentaram comportamento similar ao comportamento convencional para solos. A massa específica seca aumentou gradativamente com o aumento do teor de umidade, até se atingir um valor máximo, denominado de massa específica seca máxima $\left(\rho_{\text {dmáx }}\right)$. Para essa massa específica o teor de umidade é considerado o ponto ótimo $\left(\mathrm{w}_{\mathrm{ot}}\right)$. Observou-se ainda que a umidade ótima diminuiu e a massa específica seca máxima aumentou quando se compararam as curvas da energia modificada e da energia normal, como esperado.

Os parâmetros obtidos para a fração 0,84-0,42 mm na energia normal foram massa específica seca máxima e teor de umidade ótimo iguais a 1,480 $\mathrm{g} / \mathrm{cm}^{3}$ e $14,0 \%$ respectivamente e grau de saturação igual a $45 \%$. Para a energia modificada a massa 
específica seca máxima foi de $1,700 \mathrm{~g} / \mathrm{cm}^{3}$, o teor de umidade ótimo igual a $12 \%$ e o grau de saturação igual a 53\%. Em relação à fração < 0,42 mm, os parâmetros determinados para a energia normal foram massa específica seca máxima e teor de umidade ótimo iguais a $1,586 \mathrm{~g} / \mathrm{cm}^{3}$ e $19,8 \%$ respectivamente e grau de saturação igual a $73 \%$. No caso da energia modificada a massa específica seca máxima foi de $1,780 \mathrm{~g} / \mathrm{cm}^{3}$, o teor de umidade ótimo igual a 13,9\% e o grau de saturação igual a $68 \%$.

Depois do ensaio de compactação alguns dos pontos do ensaio foram deixados secar e posteriormente foram realizados os ensaios de análise granulométrica. Dessa forma, torna-se possível quantificar o efeito da compactação na alteração granulométrica das diferentes frações analisadas.

Figura 9 - Curvas de compactação (0,84-0,42 mm)

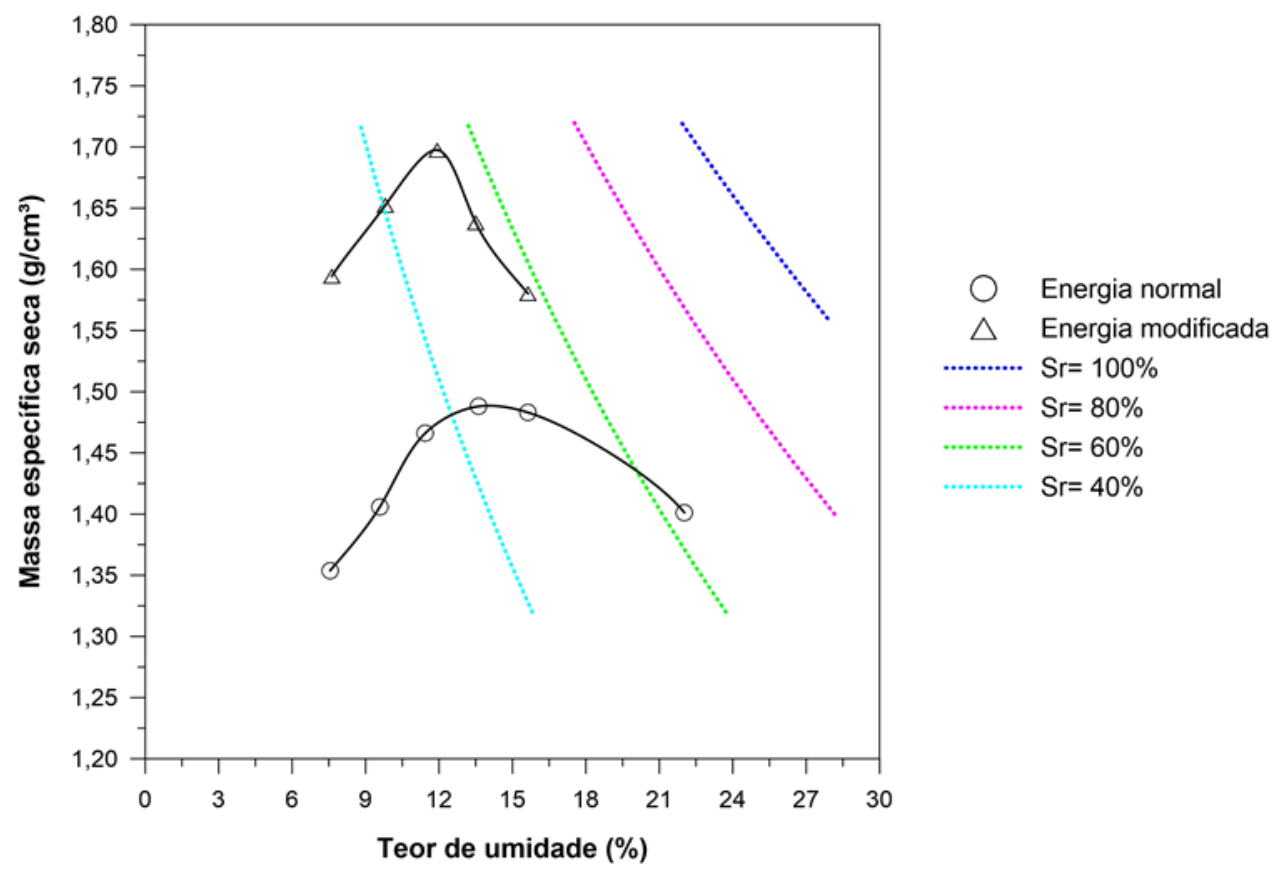

Figura 10 - Curvas de compactação $(<\mathbf{0 , 4 2} \mathbf{m m}$ )
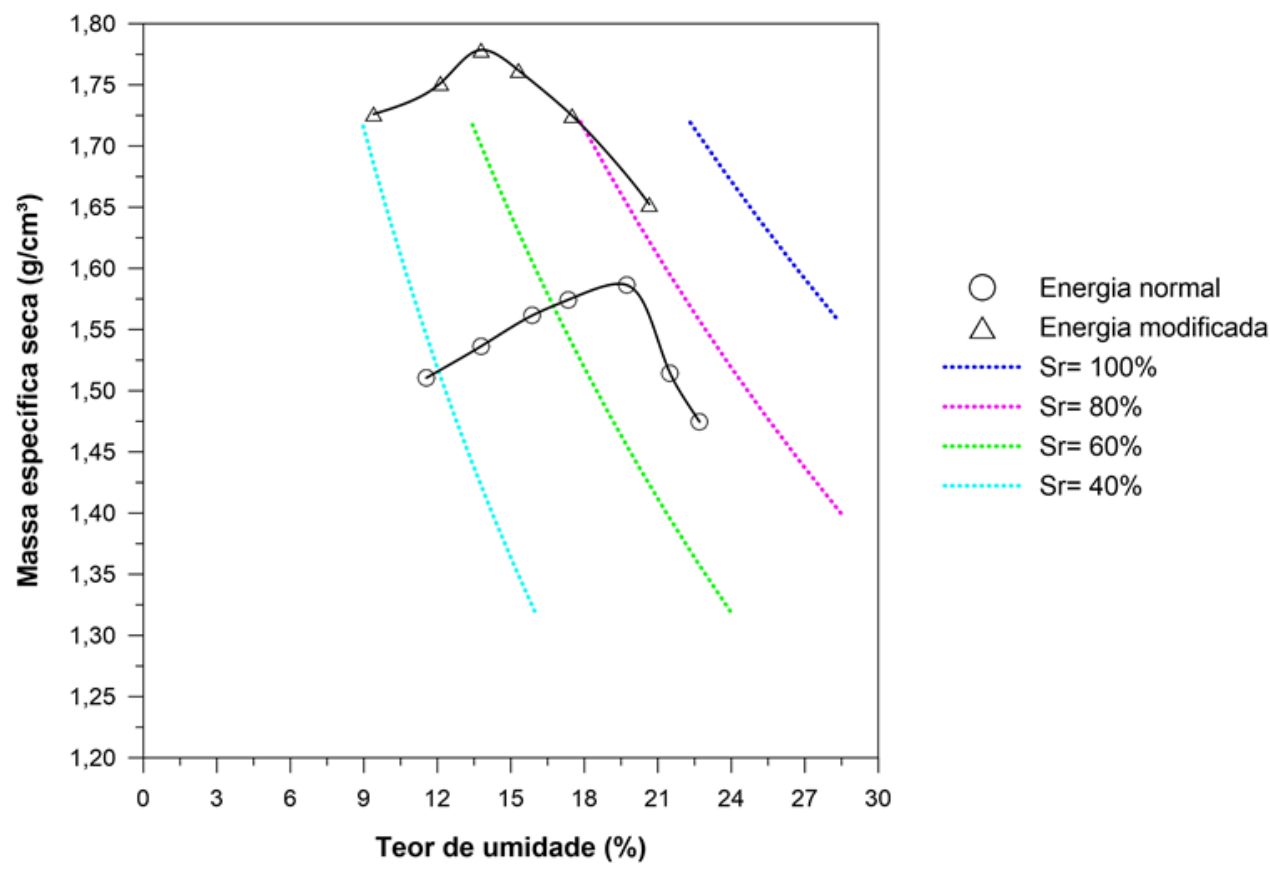


\section{Análise granulométrica}

A análise granulométrica, conforme detalhado nas Figuras 4 e 5, foi realizada em duas etapas distintas. $\mathrm{Na}$ primeira foram definidas as curvas granulométricas de referência para as diferentes frações estudadas. Essas curvas representam a distribuição granulométrica antes do processo de compactação. Na segunda etapa foram selecionados cinco pontos, compactados com teores de umidade distintos, e repetiu-se o ensaio de análise granulométrica. Posteriormente as curvas granulométricas foram comparadas a fim de se analisarem as alterações granulométricas devido ao processo de compactação.

\section{Curvas granulométricas de referência $\left(G_{R}\right)$}

A Figura 11 apresenta as curvas granulométricas adotadas como referência para cada uma das diferentes frações do RCC. A análise das curvas e dos dados da Tabela 2 permitiu observar que, apesar de algumas frações apresentarem partículas com diâmetros diferentes das faixas preestabelecidas, a separação através do peneiramento manual apresentou-se eficaz. Como a técnica de separação das partículas é manual, eventualmente podem ocorrer erros inerentes ao procedimento executivo, sobretudo aglomeração de partículas pequenas, o que acarreta um erro na interpretação do diâmetro real. A Tabela 2 ratifica esse comportamento, uma vez que essas diferenças foram observadas para as frações com faixas granulométricas inferiores. Entretanto, a divisão das frações granulométricas foi considerada satisfatória para o estudo em questão. Os dados apresentados aqui servirão de base comparativa para avaliar as alterações granulométricas provenientes do processo de compactação dos resíduos de construção e demolição.

Figura 11 - Curvas granulométricas de referência para as diferentes frações estudadas

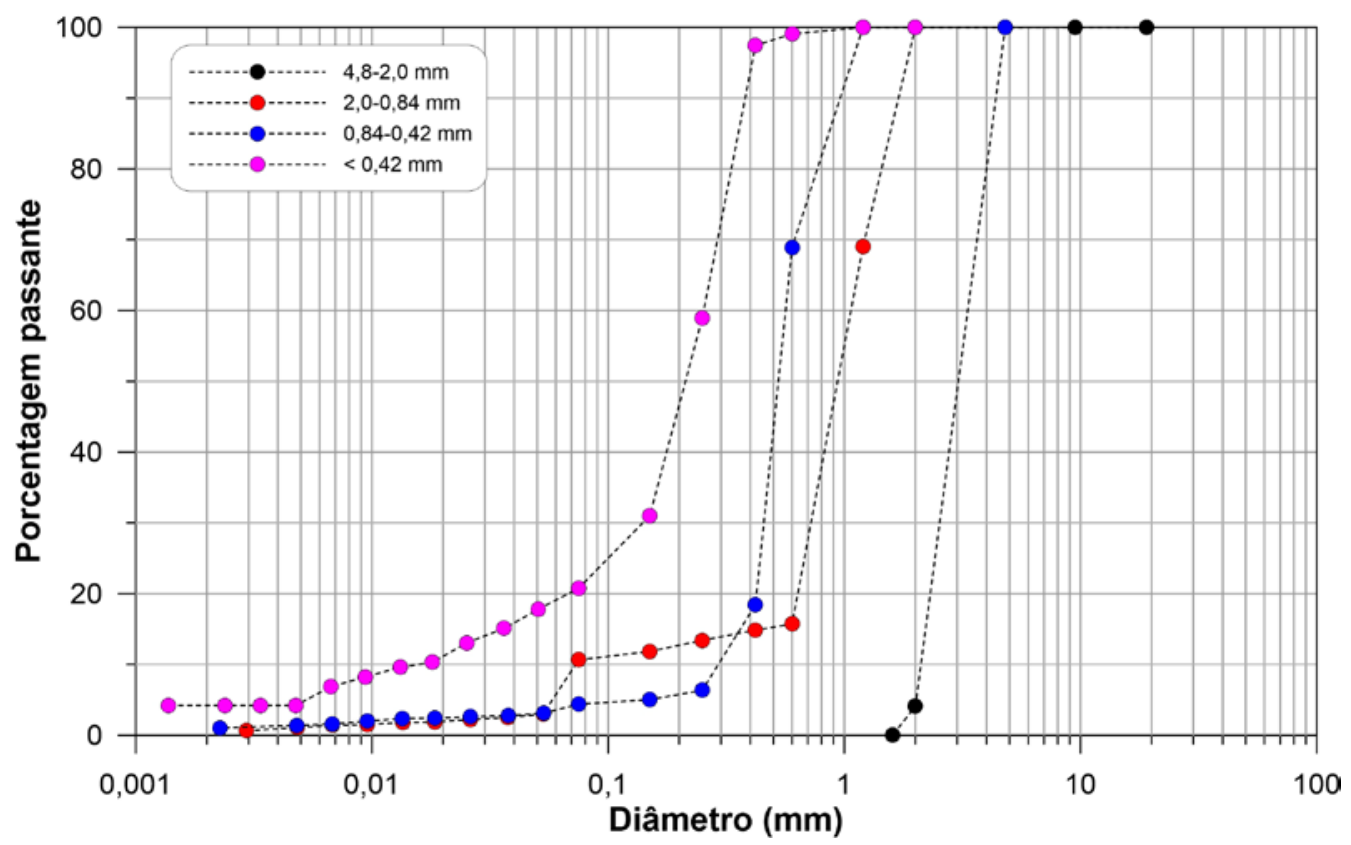

Tabela 2 - Porcentagem de material passante para as frações de RCC considerando diferentes faixas granulométricas

\begin{tabular}{|c|c|c|c|c|c|c|c|}
\hline \multicolumn{2}{|c|}{$4,8-2,0 \mathrm{~mm}$} & \multicolumn{2}{|c|}{$2,0-0,84 \mathrm{~mm}$} & \multicolumn{2}{|c|}{$0,84-0,42 \mathrm{~mm}$} & \multicolumn{2}{|c|}{$<0,42 \mathrm{~mm}$} \\
\hline$\phi(\mathrm{mm})$ & $(\%)$ & $\phi(\mathrm{mm})$ & $(\%)$ & $\phi(\mathrm{mm})$ & $(\%)$ & $\phi(\mathrm{mm})$ & $(\%)$ \\
\hline$<2,0$ & 4,1 & $<\mathbf{0 , 0 7 5}$ & 10,6 & $<0,075$ & 4,09 & $<0,075$ & 20,76 \\
\hline $2,0-3,0$ & 44,4 & $0,075-0,60$ & 5,1 & $0,075-0,25$ & 2,25 & 0,075-0,15 & 10,24 \\
\hline \multirow[t]{3}{*}{$3,0-4,8$} & 51,5 & $0,60-1,2$ & 53,3 & $0,25-0,42$ & 12,11 & $0,15-0,25$ & 27,94 \\
\hline & & $1,2-2,0$ & 31,0 & $0,42-0,6$ & 50,47 & $0,25-0,42$ & 38,42 \\
\hline & & & & $0,6-1,2$ & 31,08 & $0,42-1,2$ & 2,64 \\
\hline
\end{tabular}




\section{Curvas granulométricas após o ensaio de compactação}

A seguir são apresentadas as comparações das distribuições granulométricas para as diferentes frações com diferentes teores de umidade antes e após o ensaio de compactação. Os resultados foram analisados através da comparação entre a distribuição granulométrica obtida antes e após a compactação. A Figura 12 apresenta um exemplo de comparação das curvas granulométricas para as partículas com diâmetros entre $0,84 \mathrm{~mm}$ e 0,42 mm. Os resultados indicam que o processo de compactação induziu a quebra parcial das partículas de RCC, resultando em uma amostra com maior porcentagem de finos.

Considerando que os teores de umidade foram relativamente próximos entre si, observou-se que a energia modificada apresentou uma quebra ligeiramente superior, sobretudo devido à maior energia aplicada (cerca de 5 vezes superior). Entretanto, conforme destacado por Leite et al. (2011), a densidade também tem influência importante no processo de quebra do grão. Dessa forma, na condição de energia normal a densidade é $20 \%$ inferior (Figura 9) à energia modificada, possibilitando menor entrosamento das partículas e consequentemente uma quebra menos pronunciada.
A Figura 13 apresenta novamente a comparação entre as curvas granulométricas para as partículas com diâmetros entre 0,84 mm e 0,42 mm, compactadas com um teor de umidade próximo a $23 \%$. Os resultados indicam que a curva de distribuição granulométrica após a compactação para as energias normal e modificada foram muito próximas entre si. Para este caso, o teor de umidade também foi mantido muito próximo, e a densidade seca para a energia normal foi cerca de $10 \%$ inferior à densidade seca para a energia modificada (Figura 9). A comparação entre os resultados das Figuras 12 e 13 permite observar a influência da densidade das amostras e do teor de umidade na quebra do grão. A pequena quantidade de água na matriz do solo aumenta o atrito entre os grãos, uma vez que a água funciona como um lubrificante natural entre as partículas. Dessa forma, o maior entrosamento entre os grãos promove uma transferência mais eficiente do golpe através do esqueleto sólido, promovendo a quebra mais eficiente dos grãos. Nesse sentido, a diferença entre as densidades das amostras compactadas no ramo úmido na energia normal e modificada diminui, e consequentemente as distribuições granulométricas passam a ter comportamentos similares entre si. Esse comportamento ratifica as constatações de Leite et al. (2011) sobre a importância da densidade no processo de quebra do grão.

Figura 12 - Comparação das curvas granulométricas antes e após a compactação (grau de saturação de 40\%)

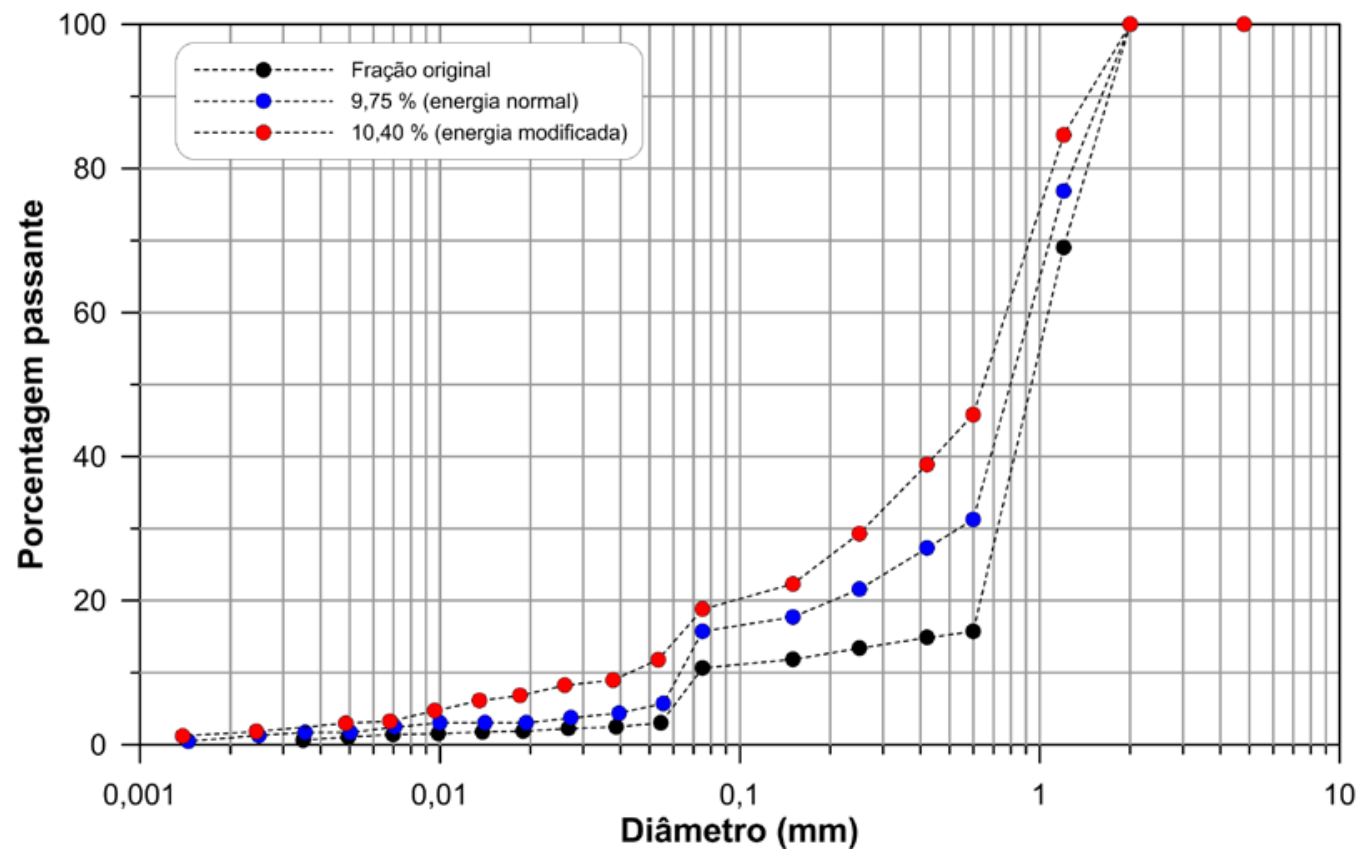


Figura 13 - Comparação das curvas granulométricas antes e após a compactação (grau de saturação de $60 \%)$

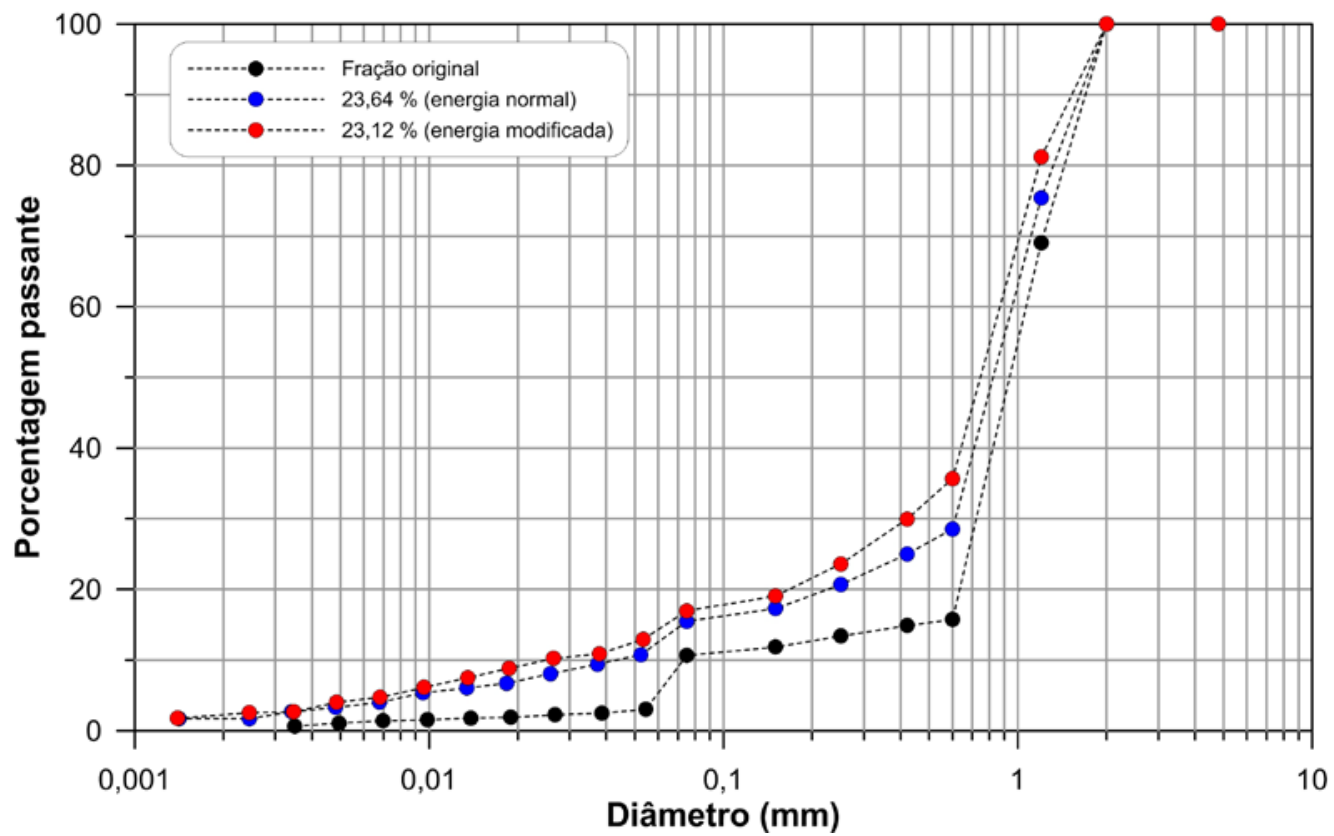

\section{Análise comparativa entre as curvas granulométricas antes e após o ensaio de compactação}

A Figura 14 apresenta o resumo dos resultados de distribuição granulométrica antes e após a compactação para a fração 4,8-2,0 mm compactada nas energias normal e modificada. Os resultados indicam que para a energia normal a alteração granulométrica é menos evidente do que para a energia modificada. Os resultados não permitiram observar nenhuma influência direta do teor de umidade. Jimenez et al. (2014) destacam que a quebra de partículas dos RCC é afetada pelo nível de energia aplicado e pelo teor de umidade adotado durante o processo de compactação. Segundo os autores, a influência do teor de umidade ocorre devido à sucção matricial desenvolvida dentro dos poros existentes, e essa análise depende da curva de retenção da amostra de RCC estudada.

Adicionalmente, os resultados indicam que para a energia normal não ocorreram alterações granulométricas para as partículas com diâmetro entre $3 \mathrm{~mm}$ e $4,8 \mathrm{~mm}$, sendo esta alteração mais pronunciada para as partículas com diâmetro entre $2 \mathrm{~mm}$ e $3 \mathrm{~mm}$, representando um decréscimo de cerca de $6 \%$ quando comparado com a granulometria original. A quebra dessas partículas ocasionou um aumento de cerca de $60 \%$ na fração granulométrica inferior a $2 \mathrm{~mm}$, conforme observado na Figura 14.
Em relação à energia modificada, observou-se um aumento considerável de quebra de grão. A fração inferior a $2 \mathrm{~mm}$ aumentou entre 3 e 5 vezes sua porcentagem inicial, sobretudo devido à quebra de grãos ocorrida nas frações entre $2 \mathrm{~mm}$ e $3 \mathrm{~mm}$. Essa fração diminuiu cerca de $16 \%$ quando comparada com a fração original. A aplicação da energia modificada acarretou uma sutil quebra dos grãos para as partículas entre $3,0 \mathrm{~mm}$ e $4,8 \mathrm{~mm}$, que não foi evidente para a energia normal.

A Figura 15 apresenta a distribuição granulométrica antes e após a compactação para a fração 2,0-0,84 $\mathrm{mm}$ considerando as energias normal e modificada de compactação. Os resultados indicam que para a energia normal a maior quebra ocorreu para as partículas compreendidas entre 1,2 $\mathrm{mm}$ e 2,0 mm, o que representa um decréscimo de $29 \%$ em relação à granulometria original. Essa alteração granulométrica resultou em um aumento de 3 a 4 vezes na fração compreendida entre $0,075 \mathrm{~mm}$ e $0,60 \mathrm{~mm}$ e um aumento de $60 \%$ na fração inferior a $0,075 \mathrm{~mm}$.

Em relação à energia modificada, observou-se que a maior quebra de grãos também ocorreu para as partículas compreendidas entre $1,2 \mathrm{~mm}$ e $2,0 \mathrm{~mm}$, o que representa um decréscimo de $45 \%$ em relação à granulometria original. A fração compreendida entre 0,6 mm e 1,2 mm apresentou redução de $22 \%$. Consequentemente, ocorreu um aumento de 4 a 5 vezes na fração compreendida entre $0,075 \mathrm{~mm}$ e $0,60 \mathrm{~mm}$ e um aumento de cerca de $70 \%$ na fração inferior a $0,075 \mathrm{~mm}$. 
Figura 14 - Distribuição granulométrica antes e após a compactação para a fração 4,8-2,0 mm considerando as energias normal e modificada de compactação

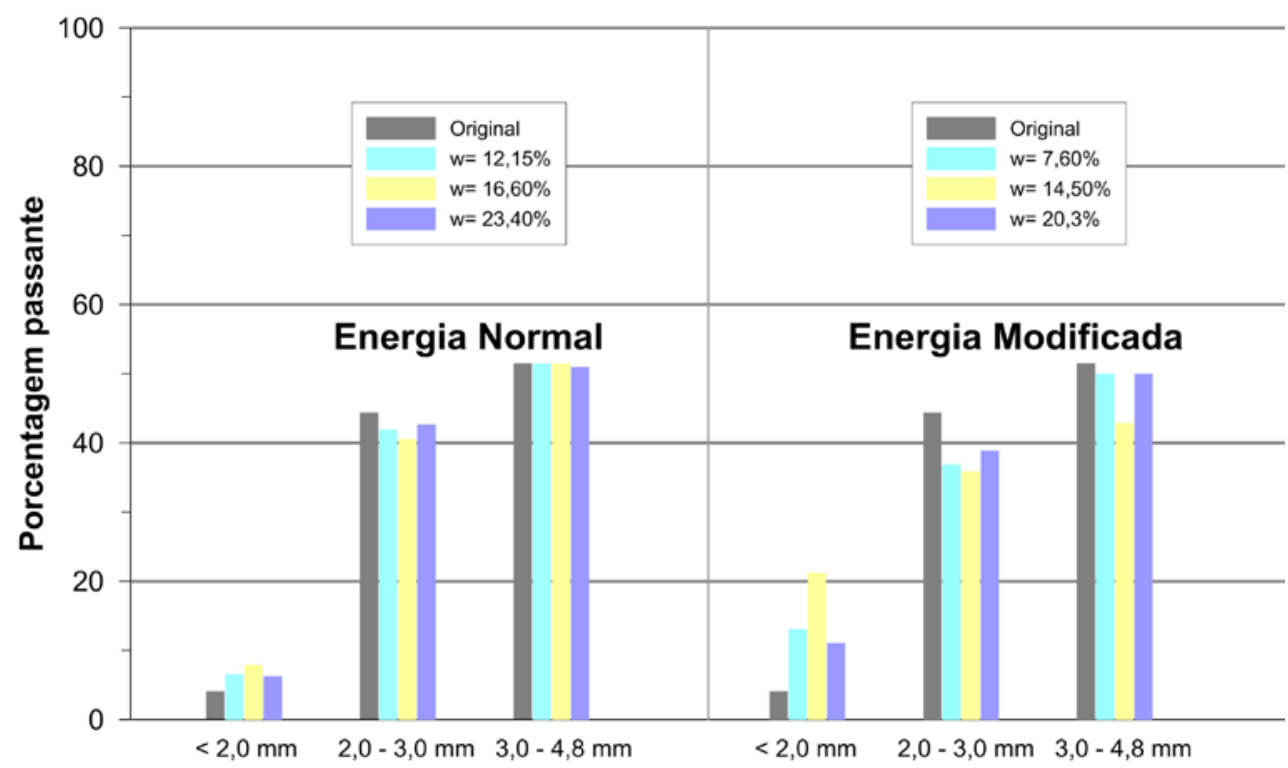

Figura 15 - Distribuição granulométrica antes e após a compactação para a fração 2, 0-0,84 mm considerando as energias normal e modificada de compactação

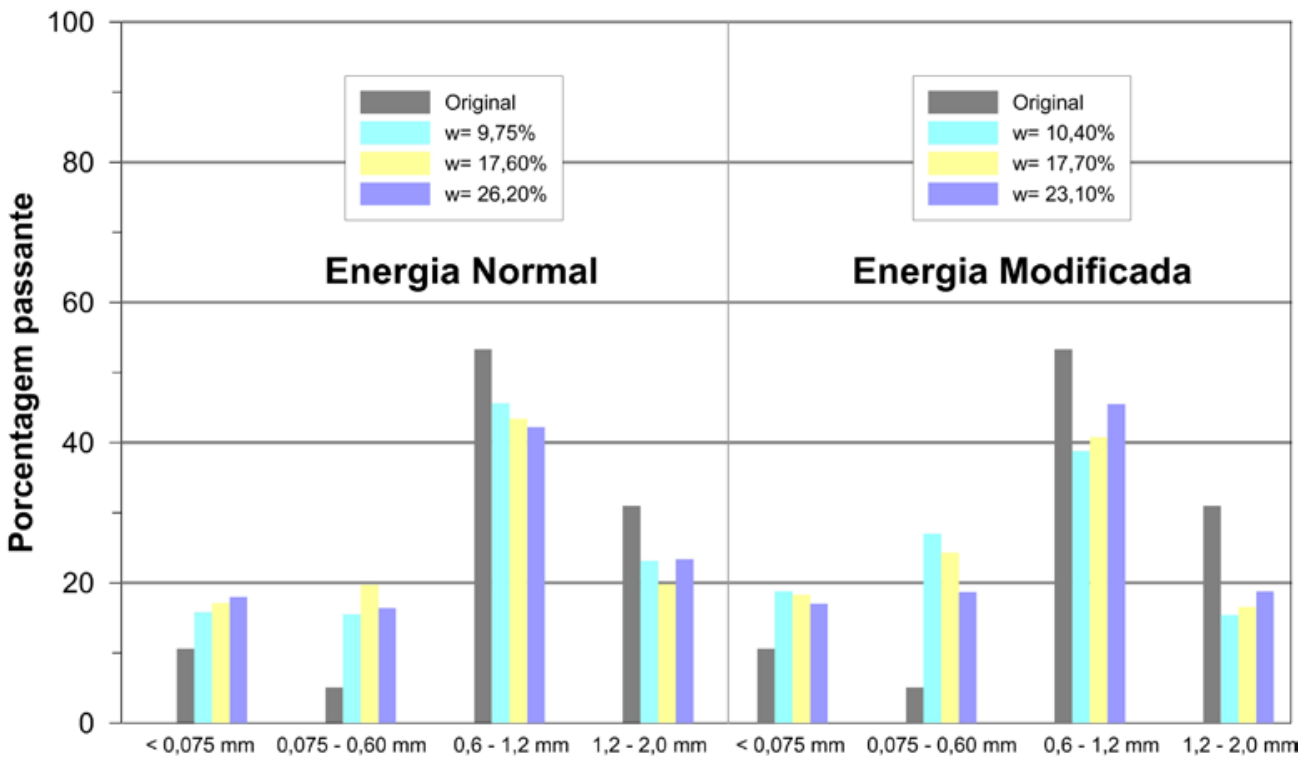

O comportamento observado para as energias normal e modificada foi similar, destacando-se que a energia modificada apresentou uma quebra de grão mais acentuada devido à aplicação de energia maior durante o processo de compactação. Além disso, para a energia modificada foi possível verificar uma ligeira influência do teor de umidade na quebra do grão. Para as frações compreendidas entre $0,60-1,2 \mathrm{~mm}$ e $1,2-2,0 \mathrm{~mm}$ os resultados indicaram que a alteração granulométrica foi mais acentuada para os menores teores de umidade e menos acentuada para os maiores teores de umidade. Isso porque a água possibilita a lubrificação das partículas, o que evita sua quebra durante a compactação.

A Figura 16 apresenta a distribuição granulométrica antes e após a compactação para a fração 0,84-0,42 mm considerando as energias normal e modificada de compactação. Os resultados indicam que tanto para a energia normal quanto para a modificada as maiores quebras de grão ocorreram para as partículas compreendidas entre 0,60 mm e 1,20 $\mathrm{mm}$, sendo essa redução para a energia normal de cerca de $22 \%$, enquanto para a energia modificada foi de 40\%. Essa alteração granulométrica proporcionou um aumento significativo na fração 
inferior a 0,075 mm, sendo cerca de 4 vezes no caso da energia modificada e 2,5 vezes no caso da energia normal. Para esta fração granulométrica não foi observada nenhuma influência do teor de umidade da amostra.

A Figura 17 apresenta a distribuição granulométrica antes e após a compactação para a fração $<0,42 \mathrm{~mm}$ considerando as energias normal e modificada de compactação. Os resultados indicam que tanto para a energia normal quanto para a modificada as maiores quebras de grão ocorreram para as partículas compreendidas entre $0,25 \mathrm{~mm}$ e 0,42 $\mathrm{mm}$, e a energia aplicada não apresentou significativa influência na alteração granulométrica desse intervalo. Para essas partículas observou-se redução de $87 \%$ quando comparada com a granulometria original.

Figura 16 - Distribuição granulométrica antes e após a compactação para a fração 0,84-0,42 mm considerando as energias normal e modificada de compactação

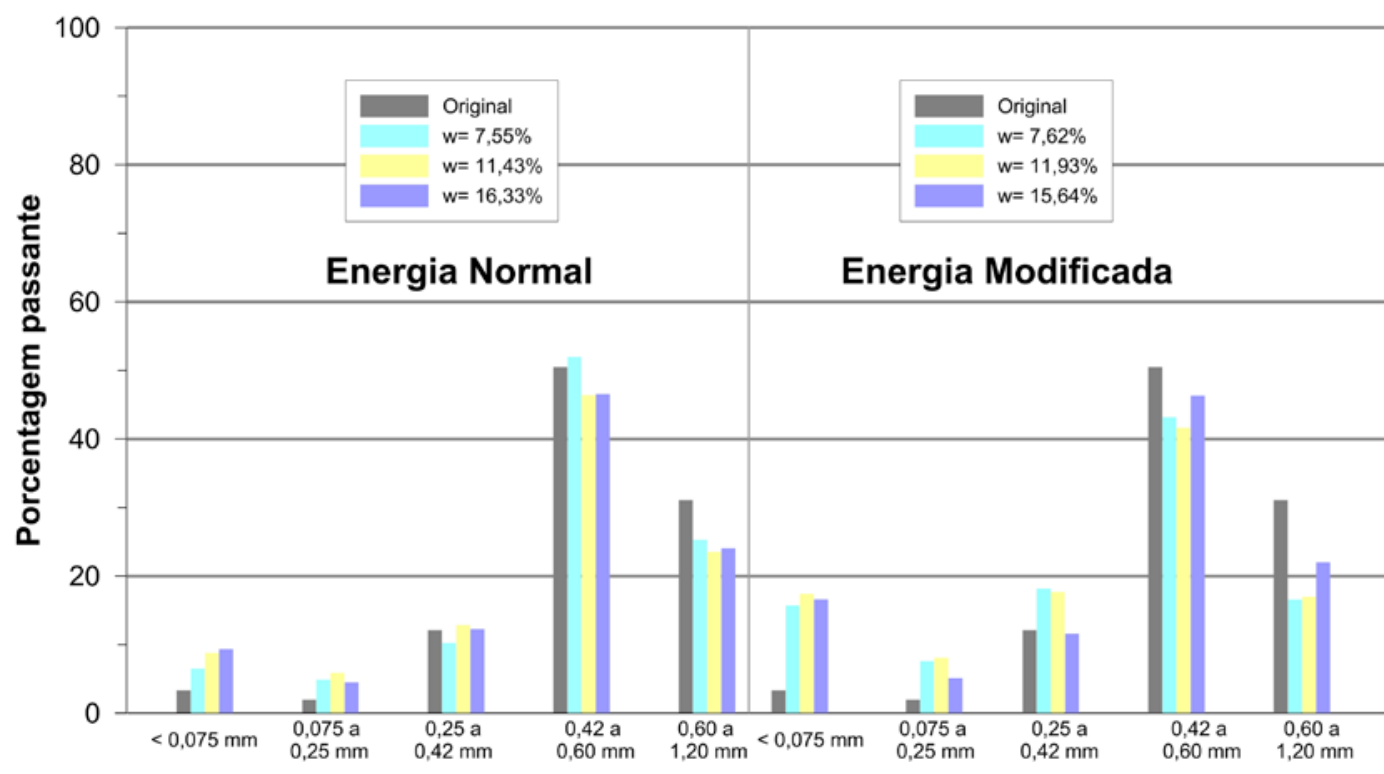

Figura 17 - Distribuição granulométrica antes e após a compactação para a fração $<0,42 \mathrm{~mm}$ considerando as energias normal e modificada de compactação

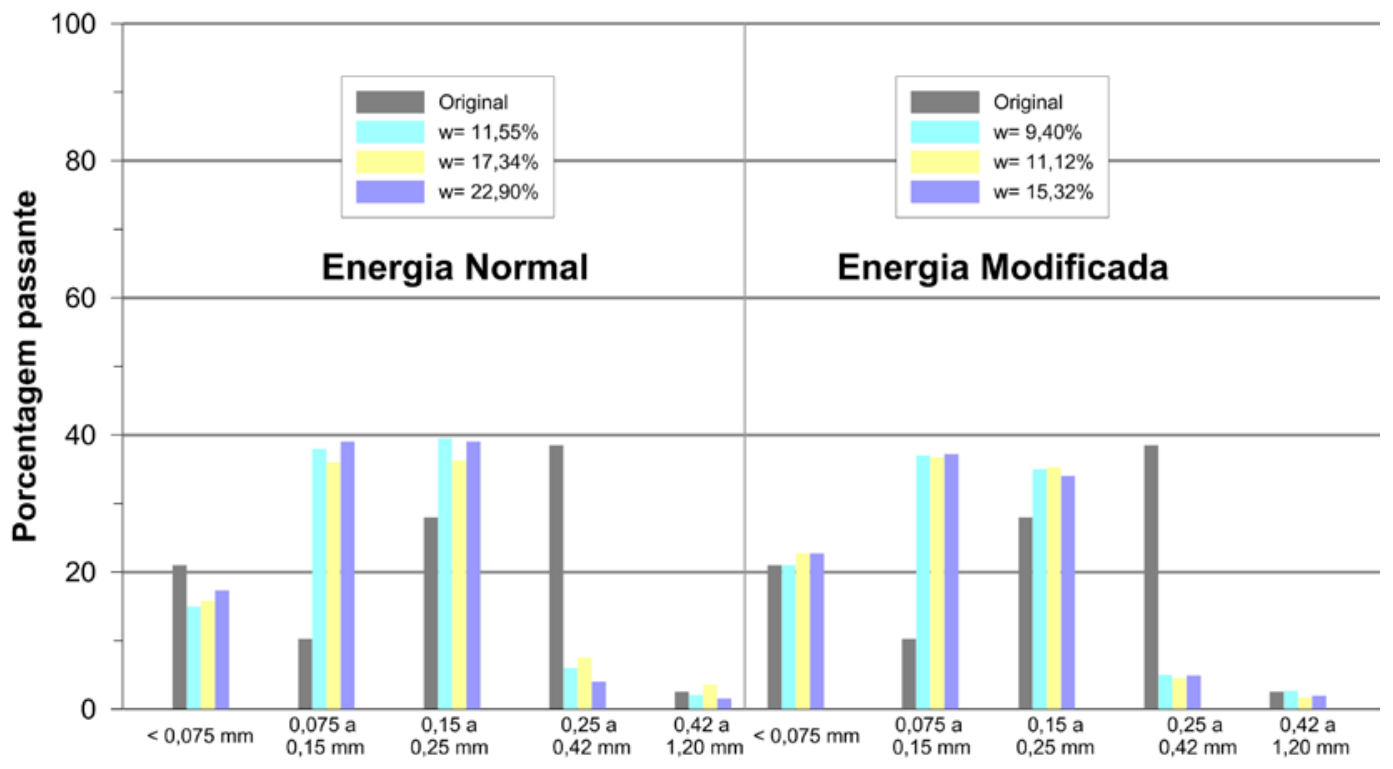


Em consequência dessa quebra, as partículas compreendidas no intervalo de $0,075 \mathrm{~mm}$ a $0,15 \mathrm{~mm}$ apresentaram aumento significativo, representando cerca de 3,5 vezes para ambas as energias. As partículas compreendidas entre $0,15 \mathrm{~mm}$ e $0,25 \mathrm{~mm}$ apresentaram um aumento entre $30 \%$ e $40 \%$ quando comparadas com a porcentagem da fração original. Os resultados indicaram que para a energia modificada a fração inferior a 0,075 mm manteve-se praticamente constante, enquanto para a energia normal essa fração diminuiu. No entanto, essa diminuição parece um contrassenso, uma vez que, como essa fração é o menor diâmetro, não poderia ocorrer sua transformação em um diâmetro inferior. Esse comportamento pode estar relacionado com o método utilizado para a quantificação da distribuição granulométrica, que consiste em um procedimento em que são realizadas leituras da densidade da solução e com base nessas informações estima-se a velocidade de sedimentação das partículas e seu diâmetro através da Lei de Stoke. Dessa forma, considera-se que para as duas energias não ocorreram diferenças significativas nas partículas com diâmetro inferior a $0,075 \mathrm{~mm}$.

De maneira geral, os resultados quantitativos apresentados nas Figuras 14 a 17 indicaram que para as diferentes frações estudadas a quebra dos grãos ocorreu em diferentes magnitudes. A fração 4,8-2,0 mm, constituída pelas maiores partículas, foi aquela que evidenciou a menor quebra de grãos. Esse comportamento apresenta-se diferente do esperado e pode estar associado a uma variação mineralógica entre as diferentes frações estudadas. Entretanto, para essa fração não foram realizados os ensaios de DRX, que possibilitariam tal confirmação. Em relação à fração 2,0-0,84 mm e à fração 0,84-0,42 mm, ambas apresentaram comportamentos similares. A fração 2,0-0,84 mm apresentou uma quebra de grãos ligeiramente superior. Observa-se que as duas frações granulométricas apresentam composição mineralógica similar (Figura 3), o que evidencia que para este caso a maior quebra ocorreu para as partículas com tamanho superior. A presença da calcita contribuiu para a ocorrência da quebra do grão, que consiste em um mineral com dureza inferior ao quartzo. A fração $<0,42 \mathrm{~mm}$ foi aquela que apresentou a maior quebra de grãos, comportamento que também pode ser explicado pela influência do tamanho do grão - em que se observou que, quanto menor o tamanho da partícula, maior a quebra do grão - e pela mineralogia (Figura 3). A constituição mineralógica dessa fração indica a presença de quartzo, albita, flogopita e calcita, sendo a flogopita (mica) e a calcita minerais com dureza muito baixa na escala de Mohs.

Os resultados não evidenciaram a influência predominante do teor de umidade na quebra dos grãos. Observou-se uma influência significativa da energia aplicada, que se tornou mais evidente para partículas maiores. Adicionalmente, para as frações granulométricas 4,8-2,0 $\mathrm{mm}$ e 2,0-0,84 mm, a densidade seca se mostrou um parâmetro de fundamental importância. Para essas frações observou-se que, quanto menor a densidade seca, maior é a possibilidade de ocorrência de quebra do grão.

\section{Considerações finais}

Este trabalho apresentou um estudo de quebra do grão em resíduos de construção civil (RCC) em decorrência do processo de compactação. O processo de compactação é uma prática de aplicação corrente em obras de pavimentação e/ou geotecnia, e por isso é de fundamental importância a avaliação de seus efeitos na quebra das partículas dos RCC.

Em relação às diferentes frações granulométricas dos RCC, observou-se que o processo de quebra está relacionado com a constituição mineralógica. Embora os RCC sejam provenientes da mesma indústria de reciclagem e da mesma coleta, quando separados em diferentes frações granulométricas observaram-se indícios da predominância de minerais diferentes. Ao contrário do esperado, a fração 4,8-2,0 mm, que é composta das partículas com maiores diâmetros, foi aquela que apresentou a menor quebra do grão. Para o melhor entendimento desse comportamento seria de fundamental importância o estudo da composição mineralógica dessa fração. Posteriormente, entre as frações 2,00,84 mm e 0,84-0,42 mm, observou-se que a fração 2,0-0,84 mm apresentou a maior quebra de grão. Os resultados da composição mineralógica indicaram que as frações são similares entre si, portanto neste caso a maior quebra encontra-se associada ao tamanho da partícula. A fração $<0,42 \mathrm{~mm}$ foi aquela que apresentou a maior quebra de grão, sendo a fração de menor tamanho e com presença de minerais micáceos e de calcita, que apresentam dureza muito baixa na escala de Mohs. Dessa forma, os resultados indicam que a constituição mineralógica está diretamente associada com o processo de quebra do grão.

Para as frações estudadas, observou-se que as curvas de compactação possuem comportamentos particulares, sendo o comportamento em alguns casos mais granular, ou seja, comportamento de material com elevada permeabilidade. Em outros casos o comportamento pode ser associado com o 
comportamento convencional observado para os solos. Considerando que a água exerce uma função importante no processo de compactação e na transferência de energia, o comportamento drenante ou não do material influencia na densidade da amostra compactada. Assim, o comportamento da densidade seca torna-se bastante variável. É importante destacar que, conforme constatado por Leite et al. (2011), a densidade da amostra possui grande relevância na quebra do grão. Assim, para as frações 4,8-2,0 mm e 2,0-0,84 $\mathrm{mm}$ os resultados deste trabalho indicaram que, conforme a densidade da amostra compactada na energia normal se aproxima da densidade da amostra compactada na energia modificada, a quebra do grão diminui consideravelmente, independentemente da energia aplicada.

Adicionalmente, os resultados apresentados não permitiram associar o comportamento de quebra do grão com o teor de umidade, conforme relatado por Jiménez et al. (2014). Em apenas alguns casos observou-se que para os maiores teores de umidade a quebra dos grãos foi menos evidenciada.

De maneira geral, os resultados apresentados neste trabalho indicam que o entendimento do processo de quebra dos grãos em amostras de RCC é um processo bastante complexo. Observou-se que, além da magnitude da energia aplicada, as condições de densidade e a constituição mineralógica da amostra exercem elevada influência no processo de quebra dos grãos.

\section{Referências}

ALEXANDRIDOU, C. et al. Physical, Chemical and Mineralogical Characterization of Construction and Demolition Waste Produced in Greece. International Journal of Civil and Environmental Engineering, v. 8, n. 9, p. 975980, 2014.

ANGULO, S. C. Caracterização de agregados de resíduos de construção e demolição reciclados e a influência de suas características no comportamento de concretos. São Paulo, 2005. 167 f. Tese (Doutorado em Engenharia Civil) Escola Politécnica, Universidade de São Paulo, São Paulo, 2005.

ANGULO, S. C. et al. Chemical-Mineralogical Characterization of C\&D Waste Recycled Aggregates From São Paulo, Brazil. Waste Management, v. 29, p. 721-730, 2009.
ARULRAJAH, A. et al. Physical Properties and Shear Strength Responses of Recycled Construction and Demolition Materials in Unbound Pavement Base/Subbase Applications. Construction and Building Materials, v. 58, p. 245-257, 2014.

ASSOCIAÇÃO BRASILEIRA DE NORMAS

TÉCNICAS. NBR 6508: grãos de solo que passam na peneira de 4,8mm: determinação da massa específica. Rio de Janeiro, 1984a.

\section{ASSOCIAÇÃO BRASILEIRA DE NORMAS}

TÉCNICAS. NBR 7181: solo: análise granulométrica. Rio de Janeiro, 1984b.

\section{ASSOCIAÇÃO BRASILEIRA DE NORMAS \\ TÉCNICAS. NBR 7182: solo: ensaio de compactação. Rio de Janeiro, 1986.}

\section{CONSELHO NACIONAL DO MEIO \\ AMBIENTE. Resolução Conama no 307. \\ Brasília, DF, 2002.}

COOP, M. R. et al. Particle Breakage During Shearing of Carbonate Sand. Géotechnique, v. 54, n. 3, p. 157-163, 2004.

DISFANI, M. M. et al. Recycled Crushed Glass in Road Work Applications. Waste Management, v. 31, p. 2341-2351, 2011.

GHAFGHAZI, M. et al. Particle Breakage and the Critical State of Sand. Soils and Foundations, v. 54, n. 3, p. 451-461, 2014.

JIMÉNEZ, A. M. G. Estudo Experimental de Um Resíduo de Construção e Demolição (RCD) Para Utilização em Pavimentação. Brasília, 2011. 123 f. Dissertação (Mestrado em Engenharia Civil) - Escola de Engenharia, Universidade de Brasília, Brasília, 2011.

JIMÉNEZ, A. M. G. et al. Water Retention Curve and Particle Breakage of Aggregates Recycled From Demolition Waste. International Journal of Civil and Architecture, v. 8, n. 9, p. 11941203, 2014.

LADE, P. V. et al. SIGNIFICANCE of Particle Crushing in Granular Materials. International Journal of Geotechnical Engineering, v. 122, n. 4, p. 309-316, 1996.

LASSO, P. R. O. et al. Avaliação do Uso de Resíduos de Construção e Demolição Reciclados Como Corretivo da Acidez do Solo. Revista Brasileira de Ciências do Solo, v. 37, p. 16591668, 2013 
LEITE, F. C. Comportamento Mecânico de Agregado Reciclado de Resíduo Sólido da Construção Civil em Camadas de Base e SubBase de Pavimentos. São Paulo, 2007. 216 f. Dissertação (Mestrado em Engenharia Civil) Escola Politécnica, Universidade Estadual de São Paulo, São Paulo, 2007.

LEITE, F. C. et al. Laboratory Evaluation of Recycled Construction and Demolition Waste for Pavements. Construction and Building Materials, v. 25, p. 2972-2979, 2011.

MATUELLA, M. F. Resíduos de Construção e Demolição Melhorados Com Cimento Portland: contribuições para a aplicação em camadas inferiores de pavimentos. Porto Alegre, 2014. 206 f. Dissertação (Trabalho de Conclusão de Curso de Engenharia Civil) - Escola de Engenharia, Universidade Federal do Rio Grande do Sul, Porto Alegre, 2014.

MENEZES, R. R. et al. Reciclagem de Resíduos da Construção Civil Para Produção de Argamassas. Cerâmica, v. 55, p. 263-270, 2009.

MIRANDA, L. F. R. et al. A Reciclagem de Resíduos de Construção e Demolição no Brasil: 1986-2008. Ambiente Construído, Porto Alegre, v. 9, n. 1, p. 57-71, jan./mar. 2009.

MITCHELL, J. K. Fundamentals of Soil

Behavior. New York: John Wiley \& Sons, 1993.
MOTTA, R. S. M. Estudo Laboratorial de Agregado Reciclado de Resíduo Sólido da Construção Civil Para Aplicação em Pavimentação de Baixo Volume de Tráfego. São Paulo, 2005. 134 f. Dissertação (Mestrado em Engenharia Civil) - Escola Politécnica, Universidade de São Paulo, São Paulo, 2005.

SANTOS, P. S. Tecnologia de Argilas Aplicada as Argilas Brasileiras. São Paulo: Edgar Blucher; USP, 1975.

SANTOS, E. C. G. Aplicação de Resíduos de Construção e Demolição Reciclados (RCD-R) em Estruturas de Solo Reforçado. São Carlos, 2007. Dissertação (Mestrado em Engenharia Civil) - Escola de Engenharia, Universidade de São Paulo, São Carlos, 2007.

SJOSTROM, C. Durability and Sustainable Use of Building Materials. In: LLEWELLYN, J. W.; DAVIES, H. (Eds.). Sustainable Use of Materials. London: BRE; Rilem, 1992.

\section{Agradecimentos}

Os autores agradecem ao CNPq (Processo $n^{\circ}$ 448606/2014-3), pelo apoio financeiro ao projeto de pesquisa, e ao Centro Brasileiro de Pesquisas Físicas (CBPF), pelo fornecimento da infraestrutura para a realização dos ensaios de DRX. Adicionalmente, os autores gostariam de expressar o seu profundo agradecimento aos revisores deste artigo.

Nathália Marques da Silva

Departamento de Engenharia Civil, Centro de Tecnologia | Universidade Estadual de Maringá | Avenida Colombo, 5790, Zona 07 | Maringá - PR - Brasil | CEP 87020-900 | Tel.: (44) 3011-4322 | E-mail: nathmdasilva@hotmail.com

Heloisa Yukie Ishida

Departamento de Engenharia Civil, Centro de Tecnologia | Universidade Estadual de Maringá | E-mail: heloisa_ishida@hotmail.com

J uliana Azoia Lukiantchuki

Departamento de Engenharia Civil, Centro de Tecnologia | Universidade Estadual de Maringá | E-mail: jazoia@yahoo.com.br

J eselay Hemetério Cordeiro dos Reis

Departamento de Engenharia Civil, Centro de Tecnologia | Universidade Estadual de Maringá | E-mail: jhcreis@uem.br

Christopher Fonseca da Silva

Departamento de Tecnologia | Universidade Estadual de Maringá | Av. Dr. Ângelo Moreira da Fonseca, 1800 | Umuarama - PR - Brasil | CEP 87506-370 | Tel.: (44) 3621-9300 | E-mail: cfsilva2@uem.br

Revista Ambiente Construído

Associação Nacional de Tecnologia do Ambiente Construído

Av. Osvaldo Aranha, 99 - 30 andar, Centro

Porto Alegre - RS - Brasil

CEP 90035-190

Telefone: +55 (51) 3308-4084

Fax: +55 (51) 3308-4054

www. seer. ufrgs. br/ ambienteconstruido

E-mail: ambienteconstruido@ufrgs.br 